Published in final edited form as:

Inorg Chem. 2019 May 20; 58(10): 6722-6730. doi:10.1021/acs.inorgchem.9b00128.

\title{
X-ray Absorption Spectroscopy as a Probe of Ligand Noninnocence in Metallocorroles: The Case of Copper Corroles
}

\author{
Hyeongtaek Lim ${ }^{\dagger}$, Kolle E. Thomas ${ }^{\ddagger}$, Britt Hedman ${ }^{\star}, \S$, Keith O. Hodgson ${ }^{\star}, \dagger$, , Abhik \\ Ghosh $^{*}, \neq$, Edward I. Solomon ${ }^{*}, \dagger, \S$ \\ † Department of Chemistry, Stanford University, Stanford, California 94305, United States \\ ‡ Department of Chemistry, UiT — The Arctic University of Norway, N-9037 Tromsø, Norway \\ $\S$ Stanford Synchrotron Radiation Lightsource, SLAC National Accelerator Laboratory, Stanford \\ University, Menlo Park, California 94025, United States
}

\section{Abstract}

The question of ligand noninnocence in $\mathrm{Cu}$ corroles has long been a topic of discussion. Presented herein is a $\mathrm{Cu} \mathrm{K}$-edge $\mathrm{X}$-ray absorption spectroscopy (XAS) study, which provides a direct probe of the metal oxidation state, of three $\mathrm{Cu}$ corroles, $\mathrm{Cu}[\mathrm{TPC}], \mathrm{Cu}\left[\mathrm{Br}_{8} \mathrm{TPC}\right]$, and $\mathrm{Cu}\left[\left(\mathrm{CF}_{3}\right)_{8} \mathrm{TPC}\right]$ (TPC $=$ meso-triphenylcorrole), and the analogous $\mathrm{Cu}$ (II) porphyrins, $\mathrm{Cu}[\mathrm{TPP}], \mathrm{Cu}\left[\mathrm{Br}_{8} \mathrm{TPP}\right]$, and $\mathrm{Cu}\left[\left(\mathrm{CF}_{3}\right)_{8} \mathrm{TPP}\right]$ ( $\mathrm{TPP}=$ meso-tetraphenylporphyrin). The $\mathrm{Cu} \mathrm{K}$ rising-edges of the $\mathrm{Cu}$ corroles were found to be about $0-1 \mathrm{eV}$ upshifted relative to the analogous porphyrins, which is substantially lower than the $1-2 \mathrm{eV}$ shifts typically exhibited by authentic $\mathrm{Cu}(\mathrm{II}) / \mathrm{Cu}$ (III) model complex pairs. In an unusual twist, the $\mathrm{Cu} K$ pre-edge regions of both the $\mathrm{Cu}$ corroles and the $\mathrm{Cu}$ porphyrins exhibit two peaks split by $0.8-1.3 \mathrm{eV}$. Based on time-dependent density functional theory calculations, the lower- and higher-energy peaks were assigned to a $\mathrm{Cu} 1 \mathrm{~s} \rightarrow 3 \mathrm{~d} x^{2}-y^{2}$ transition and a $\mathrm{Cu} 1 \mathrm{~s} \rightarrow$ corrole/porphyrin $\pi^{*}$ transition, respectively. From the $\mathrm{Cu}$ (II) porphyrins to the corresponding $\mathrm{Cu}$ corroles, the energy of the $\mathrm{Cu} 1 \mathrm{~s} \rightarrow 3 \mathrm{~d} x^{2}-y^{2}{ }^{\text {transition peak }}$ was found to upshift by $0.6-0.8 \mathrm{eV}$. This shift is approximately half that observed between $\mathrm{Cu}$ (II) to $\mathrm{Cu}$ (III) states for well-defined complexes. The Cu K-edge XAS spectra thus show that although the metal sites in the $\mathrm{Cu}$ corroles are more oxidized relative to those in their $\mathrm{Cu}$ (II) porphyrin analogues, they are not oxidized to the $\mathrm{Cu}(\mathrm{III})$ level, consistent with the notion of a noninnocent corrole. The relative importance of $\sigma$-donation versus corrole $\pi$-radical character is discussed.

\section{Graphical Abstract}

\footnotetext{
*Corresponding Authors bhedman@stanford.edu (B.H.). hodgsonk@stanford.edu (K.O.H.). abhik.ghosh@uit.no (A.G.). edward.solomon@stanford.edu (E.I.S.).

ASSOCIATED CONTENT

Supporting Information

The Supporting Information is available free of charge on the ACS Publications website at DOI: 10.1021/acs.inorg-chem.9b00128. $\mathrm{Cu}$ K-edge XAS spectra of $\left[\mathrm{Cu}(\mathrm{II})\left(\mathrm{H}_{-} 2 \mathrm{Aib}_{3}\right)\right]_{2}$ and $\mathrm{Cu}(\mathrm{III})\left(\mathrm{H}_{-} 3 \mathrm{Aib}_{3}\right)$; analysis of background subtracted pre-edge features for $\mathrm{Cu}[\mathrm{TPC}]$ and $\mathrm{Cu}[\mathrm{TPP}]$; error analysis for the second derivatives of the pre-edge regions of $\mathrm{Cu}[\mathrm{TPC}], \mathrm{Cu}[\mathrm{TPP}], \mathrm{Cu}[\mathrm{Br} 8 \mathrm{TPC}]$, and $\mathrm{Cu}[\mathrm{Br} 8 \mathrm{TPP}]$; TDDFT calculated pre-edge regions with different amounts of HF exchange $(0 \%, 10 \%$, and 20\%); DFT calculated energy level diagram; and DFT optimized Cartesian coordinates (PDF)

The authors declare no competing financial interest.
} 


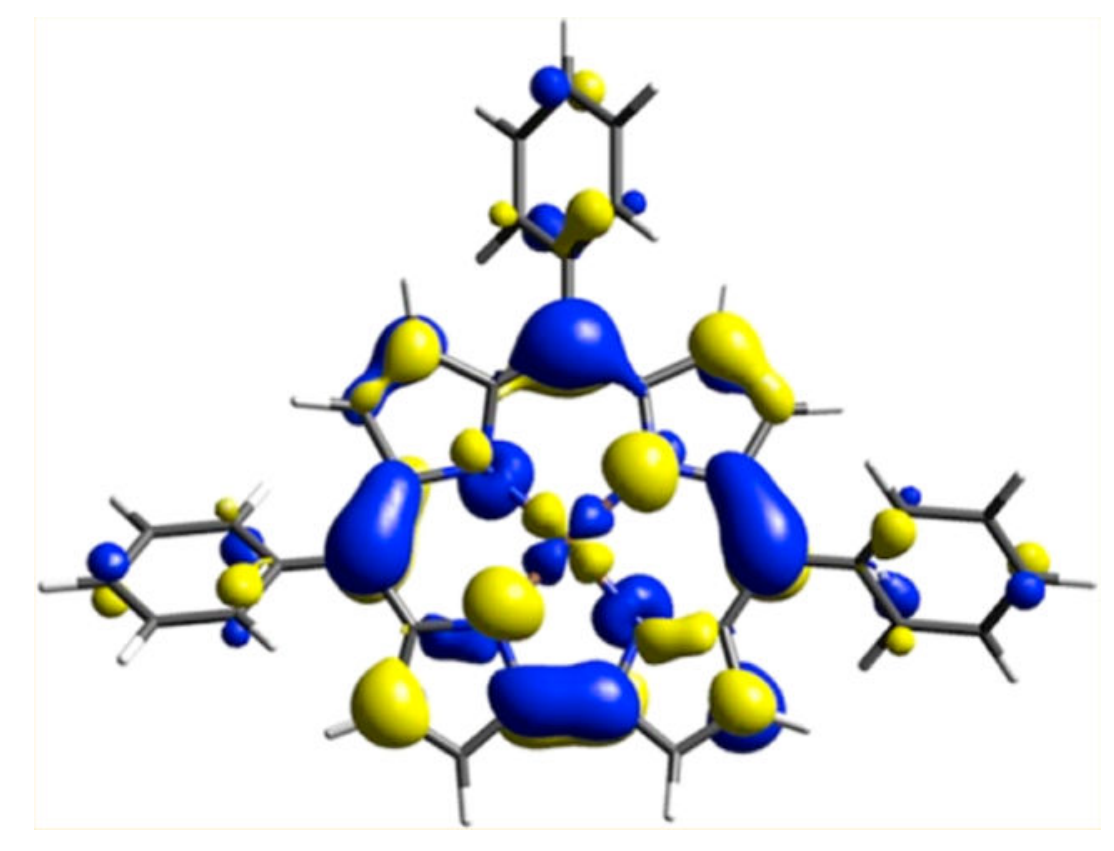

\section{INTRODUCTION}

Although superficially similar, porphyrins and corroles exhibit major differences with respect to their coordination behavior. The differences reflect different formal charges, 3for corroles versus 2 - for porphyrins, and different $\mathrm{N}_{4}$ cavity sizes for the two ligand families. As trianionic ligands with constricted $\mathrm{N}_{4}$ cavities, corroles form a wide range of formally high-valent transition metal complexes. ${ }^{1-3}$ The metal centers in many of these corrole complexes, however, are not truly high-valent; instead the corrole ligand is often partially oxidized, i.e., noninnocent. The phenomenon of ligand noninnocence is particularly common among first-row transition metal corroles ${ }^{4-9}$ and $\mathrm{Cu}$ corroles provide some of the most intensively studied examples. A variety of experimental and computational approaches have been used to shed light on the noninnocent character of $\mathrm{Cu}$ corroles, which may be summarized as follows.

Simple, sterically unhindered $\mathrm{Cu}$ corroles are generally EPR-inactive at low temperature and exhibit diamagnetic ${ }^{1} \mathrm{H}$ NMR spectra at or below room temperature. ${ }^{10,11}$ Above room temperature, however, their ${ }^{1} \mathrm{H}$ NMR spectra indicate the presence of a thermally accessible paramagnetic state, suggesting an $S=1$ excited state. ${ }^{12-16}$ Sterically hindered Cu corroles generally do not exhibit such temperature-dependent behavior, consistent with a higher singlet-triplet gap.

Hybrid density functional theory (DFT) calculations on Cu corroles, sterically hindered or not, invariably yield a broken symmetry spin density profile, consistent with significant $\mathrm{Cu}(\mathrm{II})$-corrole ${ }^{\bullet 2-}$ character. $^{3,17,18}$

The Soret maxima of $\mathrm{Cu}$ meso-tris(para-X-phenyl)corrole derivatives, $\mathrm{Cu}[\mathrm{T} p \mathrm{XPC}$, exhibit pronounced red shifts with increasing electron-donating character of the meso-aryl para 
substituent X. ${ }^{10,14,19}$ Over a long series of studies, this simple spectroscopic probe has emerged as a highly reliable signature of noninnocent metallocorroles..$^{3-10,18-20}$ In contrast, the Soret maxima of innocent metallotriarylcorroles, including $\mathrm{MoO},{ }^{21} \mathrm{RuN},{ }^{22} \mathrm{OsN},{ }^{23} \mathrm{TcO}$, ${ }^{24} \mathrm{ReO},{ }^{25}$ and $\mathrm{Au}^{18,26-28}$ corroles as well as $\mathrm{Mo}^{29}$ and $\mathrm{W}$ biscorroles, ${ }^{30}$ are largely insensitive to the nature of the para substituent $\mathrm{X}$.

Some of the most striking evidence for noninnocent corrole ligands comes from structural studies. Because of the rigidity of the direct $\mathrm{C}_{1}-\mathrm{C}_{19}$ pyrrole-pyrrole linkage, metallocorroles are generally highly resistant to nonplanar distortions such as ruffling and saddling. Yet, even sterically unhindered $\mathrm{Cu}$ corroles are inherently saddled, as required for a $\mathrm{Cu}\left(\mathrm{d}_{x^{2}-y^{2}}{ }^{2}\right)$ corrole $(\pi)$ orbital interaction, ${ }^{31}$ while sterically hindered, undecasubstituted $\mathrm{Cu}$ corroles are generally dramatically saddled. ${ }^{18,32-36}$ In contrast, other metals (with the possible exception of $\mathrm{Ag}^{18,37}$ ) result in essentially planar macrocycle conformations, again emphasizing the key importance of $\mathrm{Cu}\left(\mathrm{d}_{x^{2}-y^{2}}\right)$-corrole $(\pi)$ orbital interaction.

Finally, electrochemical and spectroelectrochemical studies on coinage metal corroles strongly suggest a noninnocent formulation for $\mathrm{Cu}$ corroles and an innocent one for $\mathrm{Au}$ corroles..$^{18,38}$

Herein, we present $\mathrm{Cu}$ K-edge X-ray absorption spectroscopy (XAS) measurements, which afford a direct probe of the metal center, on three $\mathrm{Cu}$ corroles, $\mathrm{Cu}$ [TPC], $\mathrm{Cu}\left[\mathrm{Br}_{8} \mathrm{TPC}\right]$, and $\mathrm{Cu}\left[\left(\mathrm{CF}_{3}\right)_{8} \mathrm{TPC}\right](\mathrm{TPC}=$ meso-triphenylcorrole $)$, as well as on the bona fide $\mathrm{Cu}(\mathrm{II})$ porphyrins, $\mathrm{Cu}[\mathrm{TPP}], \mathrm{Cu}-\left[\mathrm{Br}_{8} \mathrm{TPP}\right]$, and $\mathrm{Cu}\left[\left(\mathrm{CF}_{3}\right)_{8} \mathrm{TPP}\right]$ ( $\mathrm{TPP}=$ meso-tetraphenylporphyrin) (Chart 1). Recently, XAS measurements on $\mathrm{Mn},{ }^{5} \mathrm{Fe},{ }^{6} \mathrm{Co},{ }^{39} \mathrm{Ag},{ }^{37}$ and $\mathrm{Ir}^{40}$ corrole complexes have led to significant insights into the question of ligand noninnocence in these complexes. The present measurements, together with time-dependent density functional theory (TDDFT) analysis, have now shed considerable light on the electronic character of $\mathrm{Cu}$ corroles, underscoring yet again the considerable potential of XAS in elucidating the electronic structures of metal-loporphyrin-type complexes.

\section{RESULTS AND ANALYSIS}

\section{Cu K-Edge X-ray Absorption Spectroscopy.}

In metal K-edge XAS, the rising-edge energy position has been used to investigate the oxidation state of the absorbing metal center. ${ }^{41}$ Figure $1 \mathrm{~A}$ shows the rising-edge regions of the three $\mathrm{Cu}$ corroles. These are shifted to somewhat higher energies relative to their $\mathrm{Cu}$ (II) porphyrin counterparts. Specifically, the features at $\sim 8986 \mathrm{eV}$ and $\sim 8993 \mathrm{eV}$ are assigned as a Cu $1 \mathrm{~s} \rightarrow 4 \mathrm{p}+$ ligand-to-metal charge transfer (LMCT) shakedown transition and a $\mathrm{Cu} 1 \mathrm{~s}$ $\rightarrow 4 p$ transition, respectively. ${ }^{42}$ These show upshifts of $0-1 \mathrm{eV}$ in the $\mathrm{Cu}$ corroles relative to the $\mathrm{Cu}(\mathrm{II})$ porphyrins. This energy shift is rather small for a change in oxidation state from $\mathrm{Cu}$ (II) to $\mathrm{Cu}$ (III). By comparison, a previous study on $\mathrm{Cu}(\mathrm{II}) / \mathrm{Cu}$ (III) model complexes pairs revealed $\sim 1-2 \mathrm{eV}$ energy shifts in the rising-edge region. ${ }^{43}$ The present results suggest that the metal centers in the $\mathrm{Cu}$ corroles are more oxidized than those in the $\mathrm{Cu}(\mathrm{II})$ porphyrins, but not to the level of authentic $\mathrm{Cu}$ (III) complexes. The energy shift in the rising-edge region, however, cannot be used as an authoritative analytic marker for distinguishing $\mathrm{Cu}$ (II) 
and $\mathrm{Cu}(\mathrm{III})$ complexes, since it varies significantly (by $\sim 0-2 \mathrm{eV}$ ) among different pairs of complexes. $^{43}$

In contrast, the $\mathrm{Cu} \mathrm{K}$ pre-edge feature, which originates from a $\mathrm{Cu} 1 \mathrm{~s} \rightarrow 3 \mathrm{~d}$ transition, provides a more direct measure of the $\mathrm{Cu}$ oxidation state. Typically, the pre-edge features of $\mathrm{Cu}$ (II) and $\mathrm{Cu}$ (III) complexes fall at $\sim 8979 \mathrm{eV}$ and $\sim 8981 \mathrm{eV}$, respectively; thus, an $\sim 2 \mathrm{eV}$ shift is observed for an oxidation state change from $\mathrm{Cu}$ (II) to $\mathrm{Cu}$ (III) (see example in Figure $\mathrm{S} 1) .{ }^{43}$ Figure $1 \mathrm{~B}$ presents the pre-edge features for both the $\mathrm{Cu}$ corroles and the $\mathrm{Cu}(\mathrm{II})$ porphyrins. Because the features are broad and weak, they have also been presented as their second derivatives (insets within Figure 1B). The insets within Figure 1B show that there are two peaks in the pre-edge regions for both the $\mathrm{Cu}$ corroles and the $\mathrm{Cu}$ (II) porphyrins (indicated by horizontal brackets in the Figure 1B insets). Note that smoothed second derivatives were employed here because of the noisy nature of the nonsmoothed second derivatives owing to the weak nature of the pre-edge features. Although smoothing can be used to show general trends that may be hidden in noisy data, it can at times also introduce artifacts. Thus, for $\mathrm{Cu}[\mathrm{TPC}]$ and $\mathrm{Cu}[\mathrm{TPP}]$, which yielded the best data, we also analyzed the background subtracted pre-edge features to determine whether two peaks are indeed required for the pre-edge regions (for details, see Figure S2 and Supporting Information (SI) text). Error levels in the smoothed second derivatives were then evaluated for the Cu[TPC], $\mathrm{Cu}[\mathrm{TPP}], \mathrm{Cu}\left[\mathrm{Br}_{8} \mathrm{TPC}\right]$, and $\mathrm{Cu}\left[\mathrm{Br}_{8} \mathrm{TPP}\right]$ data sets, which had better signal-to-noise ratios (for details, see Figure S3 and SI text). This error analysis clearly showed the presence of two peaks in the pre-edge regions for each of the four compounds. The smoothed second derivatives for $\mathrm{Cu}\left[\left(\mathrm{CF}_{3}\right)_{8} \mathrm{TPC}\right]$ and $\mathrm{Cu}-\left[\left(\mathrm{CF}_{3}\right)_{8} \mathrm{TPP}\right]$ exhibit a worse signal-to-noise ratio, owing to the limited amounts available for these compounds because of difficult syntheses.

Subsequently, the same two-peak fit of the pre-edge feature was employed for $\mathrm{Cu}\left[\left(\mathrm{CF}_{3}\right)_{8} \mathrm{TPC}\right]$ and $\mathrm{Cu}\left[\left(\mathrm{CF}_{3}\right)_{8} \mathrm{TPP}\right]$ (see Experimental Section). For the series of compounds studied, these two peaks are split by $0.8-1.3 \mathrm{eV}$ (Table 1). Going from the $\mathrm{Cu}$ (II) porphyrins to the corresponding $\mathrm{Cu}$ corrole, the energies of both peaks upshift, the first by $0.6-0.8 \mathrm{eV}$ and the second by $0.8-1.1 \mathrm{eV}$ (Table 1). A $\mathrm{Cu} \mathrm{K}$ pre-edge region with two peaks is quite unusual and accordingly the assignment of the peaks is considered in the next section. The key point, however, is that the shifts in each of the porphyrin/corrole pairs are on the order of $0.6-1.1 \mathrm{eV}$, which is approximately half that observed between $\mathrm{Cu}$ (II) to $\mathrm{CU}(\mathrm{III})$ states for well-defined complexes. The $\mathrm{Cu} \mathrm{K}$-edge XAS spectra thus show that although the metal sites in the $\mathrm{Cu}$ corroles are oxidized compared to those in their $\mathrm{Cu}$ (II) porphyrin analogues, they are not oxidized to the $\mathrm{Cu}$ (III) level.

\section{Time-Dependent Density Functional Theory Analysis.}

TDDFT has been shown to provide reasonably good simulations of experimentally observed metal pre-edge regions and accordingly can be used for spectral assignment and quantitative analysis. 5,6,39,44-47 For assigning the two peaks observed in the pre-edge region, TDDFT calculations with the BP86 functional are first considered for the $\mathrm{Cu}$ (II) porphyrins (red spectra in Figure S4A, B, and C). It may be noted that the absorption energies in the TDDFT calculations are different from those in the experimental data. This is a well-known error in the DFT calculations which have limitations in modeling the potential at the nucleus. The difference in the calculated and experimental absorption energies depends on the functional 
and the basis set used, but the error is systematic and thus can be calibrated for the particular functional and basis set. In the present study, this issue is not of concern, since only energy differences among peaks are considered. In the TDDFT/BP86 calculations (red spectra in Figure S4A, B, and C), two transitions contribute to the peak at $\sim 8952.3 \mathrm{eV}$ for the $\mathrm{Cu}(\mathrm{II})$ porphyrins (Table 2; note that features at $>8954 \mathrm{eV}$ are part of the rising-edge region): one is the $\mathrm{Cu} 1 \mathrm{~s} \rightarrow 3 \mathrm{~d}_{x^{2}-y^{2}}$ transition, and the other is the $\mathrm{Cu} 1 \mathrm{~s} \rightarrow$ porphyrin $\pi^{*}\left(\mathrm{e}_{\mathrm{g}}\right)$ transitions. Figure 2A and Figure 3A, B, and C show the energy level diagram and the unoccupied molecular orbitals, respectively, associated with these valence levels. Although having two transitions in the pre-edge region in the TDDFT calculation is consistent with the two observed experimental peaks, their energy separation with the BP86 functional (0\% HartreeFock (HF) exchange) is $\sim 0.7 \mathrm{eV}$ smaller than the experimental value $(\sim 1 \mathrm{eV})$ (Table 1 and Table 2). DeBeer and co-workers systematically compared the experimental and TDDFT calculated pre-edge regions for a series of Mn complexes and showed that the energy position of a Mn 1s $\rightarrow$ ligand $\pi^{*}$ transition relative to that of a Mn $1 \mathrm{~s} \rightarrow 3 \mathrm{~d}$ transition is highly dependent on the amount of HF exchange used in the TDDFT calculations. ${ }^{46}$ Thus, TDDFT calculations with varying amounts of $\mathrm{HF}$ exchange were performed on the $\mathrm{Cu}$ (II) porphyrins to determine the amount of $\mathrm{HF}$ exchange required to simulate the experimental spectra (Figure 1 for the experimental spectra; Figure S4 and Figure 4 for the TDDFT simulations). TDDFT with the B3LYP functional (20\% HF exchange) also shows two transitions: one at $\sim 8987 \mathrm{eV}\left(\mathrm{Cu} 1 \mathrm{~s} \rightarrow 3 \mathrm{~d}_{x^{2}-y^{2}}\right)$ and the other at $\sim 8991-8992 \mathrm{eV}(\mathrm{Cu} 1 \mathrm{~s}$ $\rightarrow$ porphyrin $\pi^{*}$ ); these are separated by $\sim 4-5 \mathrm{eV}$ which is much larger than the experimentally observed energy splitting of $\sim 1 \mathrm{eV}$ (Table 2 and red spectra in Figure S4G, $\mathrm{H}$, and I). This energy separation becomes smaller as the amount of HF exchange decreases. Two transitions are calculated at $\sim 8971 \mathrm{eV}$ and $\sim 8973 \mathrm{eV}$ with $10 \% \mathrm{HF}$ exchange (Table 2 and red spectra in Figure S4D, E, and F), showing an $\sim 2 \mathrm{eV}$ energy separation that is still larger than the experimental value. It is found that the experimental splittings of $\sim 1 \mathrm{eV}$ are reproduced with TDDFT calculations containing 5\% HF exchange (Table 2 and red spectra in Figure 4).

The $\mathrm{Cu}$ corroles also exhibit two pre-edge peaks split by $1.2-1.3 \mathrm{eV}$ (as shown by the experimental spectra in solid lines in Figure 1), and TDDFT calculations with 0-20\% HF exchange were again performed to assign these peaks (Table 2 and black spectra in Figure $\mathrm{S} 4$ and Figure 4). As for the $\mathrm{Cu}(\mathrm{II})$ porphyrins, TDDFT calculations with $5 \% \mathrm{HF}$ exchange satisfactorily reproduce the experimental spectra (Table 2 and black spectra in Figure 4), yielding a splitting of $\sim 1.3 \mathrm{eV}$ between the two transitions. The assignment of these two peaks is similar to that for the $\mathrm{Cu}$ (II) porphyrins: one is the $\mathrm{Cu} 1 \mathrm{~s} \rightarrow 3 \mathrm{~d} x^{2}-y^{2}$ transition, and the other corresponds to near-degenerate $\mathrm{Cu} 1 \mathrm{~s} \rightarrow$ corrole $\pi^{*}\left(\mathrm{a}_{2}+\mathrm{b}_{1}\right)$ transitions; these valence levels are shown in Figure $2 \mathrm{~B}$ and $\mathrm{C}$, and the relevant molecular orbitals are shown in Figure 3D, E, and F. As in the case of the $\mathrm{Cu}$ (II) porphyrins, the energy separation between these two transitions increases with increasing amounts of HF exchange. It is important to note that in TDDFT with $20 \% \mathrm{HF}$ exchange for the $\mathrm{Cu}$ corroles, but not for the $\mathrm{Cu}$ (II) porphyrins, there is an additional feature at $\sim 8989.8 \mathrm{eV}$ which appears $\sim 2 \mathrm{eV}$ higher than the $\mathrm{Cu} 1 \mathrm{~s} \rightarrow 3 \mathrm{~d} x^{2}-y^{2}$ transition (indicated by arrows in Figure S4G, H, and I). In the 
TDDFT calculations with $20 \% \mathrm{HF}$ exchange, there is spin polarization of the energy level diagram due to the increased exchange (Figure 2C and the 20\% HF exchange DFT calculation in Figure S5). Specifically, the electrons in the $\mathrm{b}_{1}$-HOMO of the $\mathrm{Cu}$ corroles are spin-polarized, which leads to a hole in the corrole $b_{1} \mathrm{HOMO}$ (which is analogous to the porphyrin $\mathrm{a}_{2 \mathrm{u}} \mathrm{HOMO}$ ) and an electron in the $\mathrm{Cu} 3 \mathrm{~d}_{x^{2}-y^{2}}$ orbital. Thus, the additional feature at $\sim 8989.8 \mathrm{eV}$ originates from a new possible transition from the $\mathrm{Cu} 1 \mathrm{~s}$ orbital to the corrole $\mathrm{b}_{1}$ orbital. Alternatively, the TDDFT calculations with 0-10\% HF exchange do not exhibit this additional feature (Table 2 and black spectra in Figure S4A-F and Figure 4), since the amount of the exact exchange is not high enough to result in significant spin polarization; two electrons thus occupy the corrole $\mathrm{b}_{1}$ HOMO while the $\mathrm{Cu} 3 \mathrm{~d}_{x^{2}-y^{2}}{ }^{\text {orbital is empty }}$ (Figure 2B and the 5\% HF exchange DFT calculation in Figure S5). It should be noted that Kar and co-workers performed $\mathrm{Cu}$ K-edge XAS on the 10-(2,4,5-trimethoxy-phenyl)-5,15bis(4-cyanophenyl)corrolatocopper complex and argued for a $\mathrm{Cu}(\mathrm{III})$ description based on the observation of a pre-edge peak ( $\mathrm{Cu} 1 \mathrm{~s} \rightarrow 3 \mathrm{~d}$ transition) at $8980.5 \mathrm{eV}$ and a $\mathrm{Cu} 1 \mathrm{~s} \rightarrow 4 \mathrm{p}$ + LMCT shakedown peak at $8986.5 \mathrm{eV}^{48}$ The very weak nature of the pre-edge absorption led these authors to fit only a single peak, whereas the present analysis based on second derivatives shows that the pre-edge region in fact consists of two peaks. This analysis is also supported by TDDFT calculations.

\section{DISCUSSION}

The issue of ligand noninnocence in $\mathrm{Cu}$ corroles has been addressed in many studies. In this study, $\mathrm{Cu}$ K-edge XAS has been used to probe the $\mathrm{Cu}$ oxidation state in the $\mathrm{Cu}$ corroles and the analogous $\mathrm{Cu}(\mathrm{II})$ porphyrins. The XAS data revealed two peaks in the pre-edge regions for both classes of complexes; the lower- and higher-energy peaks were assigned to the $\mathrm{Cu}$ $1 \mathrm{~s} \rightarrow 3 \mathrm{~d}_{x^{2}-y^{2}}$ and $\mathrm{Cu} 1 \mathrm{~s} \rightarrow$ corrole/porphyrin $\pi^{*}$ transitions, respectively, by means of TDDFT calculations (Figure 2). The oxidation state of the $\mathrm{Cu}$ center can be directly related to the energy position of the lower-energy peak. For the $\mathrm{Cu}(\mathrm{II})$ porphyrins, the $\mathrm{Cu} 1 \mathrm{~s} \rightarrow$

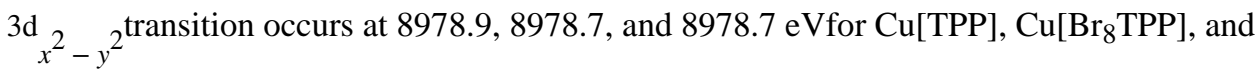
$\mathrm{Cu}\left[\left(\mathrm{CF}_{3}\right)_{8} \mathrm{TPP}\right]$, respectively (Figure 1 and Table 1 ). For the corresponding $\mathrm{Cu}$ corroles, the $\mathrm{Cu} 1 \mathrm{~s} \rightarrow 3 \mathrm{~d}_{x^{2}-y^{2}}$ transitions are upshifted to $8979.7,8979.3$, and $8979.3 \mathrm{eV}$, respectively.

In other words, the porphyrin-to-corrole upshifts are $0.8,0.6$, and $0.6 \mathrm{eV}$ for the $\beta$ - $\mathrm{H}_{8}, \beta-\mathrm{Br}_{8}$, and $\beta-\left(\mathrm{CF}_{3}\right)_{8}$ substitution patterns, respectively. These energy upshifts are all less than half that for a genuine oxidation state change from $\mathrm{Cu}$ (II) to $\mathrm{CU}$ (III) $(\sim 2 \mathrm{eV})$. The $\mathrm{Cu}$ centers of the $\mathrm{Cu}$ corroles thus are best described as somewhat oxidized relative to the $\mathrm{Cu}$ (II) porphyrin, but not up to a $\mathrm{Cu}(\mathrm{III})$ state.

Wieghardt and co-workers recently used $\mathrm{Cu}$ K-edge XAS and computations on highly covalent $\mathrm{Cu}$ complexes to suggest that the $\mathrm{Cu} \mathrm{K}$ pre-edge feature may be better described as a metal-to-ligand charge transfer transition because the LUMO has the significant ligand character relative to the $\mathrm{Cu}$ d orbital character, ${ }^{49}$ a notion that has also been echoed in other recent $\mathrm{Cu}$ K-edge XAS studies. ${ }^{50-52}$ These authors found an energy upshift of the pre-edge feature for the complexes with lower effective nuclear charge $\left(\mathrm{Z}_{\mathrm{eff}}\right)$ and suggested that the 
$\mathrm{Cu} \mathrm{K}$ pre-edge energy upshift is not necessarily correlated with an increase of the $\mathrm{Cu}$ oxidation state. Both $\mathrm{Z}_{\mathrm{eff}}$ and ligand field (LF) strength contribute to the energy shift in the $\mathrm{Cu} \mathrm{K}$ pre-edge feature. In a full oxidation state change, the increase in $\mathrm{Z}_{\mathrm{eff}}$ typically induces large perturbations in the LF, which raises the energy of the LUMO (which contains $\mathrm{Cu} d$ orbital character); i.e., these two factors are highly coupled. We previously used $\mathrm{Cu} \mathrm{K}$-edge, L-edge XAS, and TDDFT calculations to separate the contribution of $Z_{\mathrm{eff}}$ and the LF strength, and showed that, in going from $\mathrm{Cu}$ (II) to $\mathrm{Cu}$ (III) in sets of comparable model complexes, the $\sim 2 \mathrm{eV}$ energy upshifts in the $\mathrm{Cu}$ L-edge peaks as well as the $\mathrm{Cu} \mathrm{K}$ pre-edge feature are mostly dominated by the increase in LF strength. ${ }^{53}$ In Wieghardt and co-workers' calculations, the LF strengths were higher for the complexes with lower $\mathrm{Z}_{\text {eff }}$ and thus their observation of an energy upshift of the pre-edge feature in complexes with lower $Z_{\mathrm{eff}}$ is in line with our previous analysis. In the present study, $\mathrm{Cu}$ (II) porphyrins are used as $\mathrm{Cu}$ (II) references for the $\mathrm{Cu}$ corroles which have similar ligand environments. For these complexes, an increase in the oxidation (i.e., increased $Z_{\text {eff }}$ ) is coupled to an increase in the LF strength, and thus the use of the pre-edge energy as a diagnostic of the $\mathrm{Cu}$ oxidation state is reasonable. It is worth noting that $\mathrm{Cu} \mathrm{K}$ pre-edge energy shifts were recently used to study the metal oxidation state in $\mathrm{Cu} N$-confused corroles. ${ }^{54}$ This study showed that the $\mathrm{N}$ confused corroles can stabilize the $\mathrm{Cu}$ (III) state based on experimental and computational data, including an $\sim 2 \mathrm{eV}$ upshift of the pre-edge feature in going from the $\mathrm{Cu}$ (II) $\mathrm{N}$-confused porphyrin to the $\mathrm{Cu} N$-confused corrole. Likewise, $\mathrm{Cu}$ azulicorrole, which is planar (i.e., not at all saddled), has been tacitly assumed to incorporate a $\mathrm{Cu}(\mathrm{III})$ center. ${ }^{55}$

Two orbital pathways can account for a $\mathrm{Cu}$ (II)-like center in $\mathrm{Cu}$ corroles: (1) strong covalent

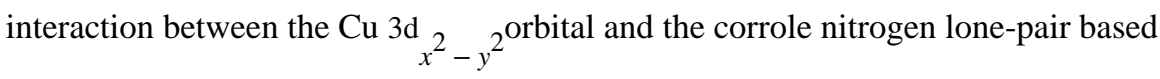
molecular orbital whose energy level is schematically shown as $b_{2}$ in Figure 2 (analogous to porphyrin $b_{1 \mathrm{~g}}$ ) and (2) electron donation from the corrole $b_{1}$-HOMO (analogous to the porphyrin $\mathrm{a}_{2 \mathrm{u}}$-HOMO) into the $\mathrm{Cu} 3 \mathrm{~d}_{x^{2}-y^{2}}$ orbital. It has been suggested that the substantial saddling of $\mathrm{Cu}$ corroles, which facilitates the otherwise symmetry-forbidden $\mathrm{Cu}\left(3 \mathrm{~d} x^{2}-y^{2}\right)^{-}$ corrole $\left(\mathrm{b}_{1}-\mathrm{HOMO}\right.$ ) orbital interaction (a $\sigma-\pi$ interaction) (Figure 5), would lead to a spin

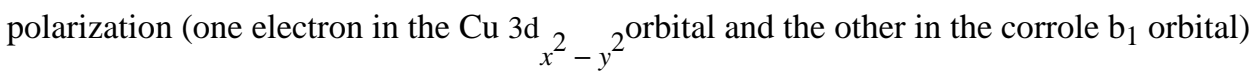
and antiferromagnetic coupling between the two electrons. ${ }^{11-19,31-36,38}$ In other words, the second mechanism has been proposed to be largely responsible for the $\mathrm{Cu}$ (II) character in $\mathrm{Cu}$ corroles. Such a picture has been supported by other data including the strong substituent dependence of the Soret maxima, ${ }^{10,14,19}$ the temperature dependence of ${ }^{1} \mathrm{H}$ NMR indicating the presence of a thermally accessible triplet state, ${ }^{13,14}$ and the relatively high reduction potentials (indicating ease of reduction). ${ }^{10,14,18,19,34}$ The present study shows that the experimental $\mathrm{Cu} \mathrm{K}$ pre-edge features are best reproduced with TDDFT calculations with only $5 \% \mathrm{HF}$ exchange, which do not result in spin polarization. While it is tempting to interpret this last finding as less supportive of a diradical state, in balance a determination of the relative importance of the two orbital pathways should be regarded as unsettled.

Finally, it is worth considering the steric effect of $\beta$ substituents on the $\mathrm{Cu}$ (II) character in the $\mathrm{Cu}$ corroles. Although even sterically unhindered $\mathrm{Cu}$ corroles are inherently saddled, 
bulky $\beta$ substituents enhance the degree of saddling, which increases in the order $\mathrm{Cu}[\mathrm{TPC}]<$ $\mathrm{Cu}\left[\mathrm{Br}_{8} \mathrm{TPC}\right]<\mathrm{Cu}\left[\left(\mathrm{CF}_{3}\right)_{8} \mathrm{TPC}\right] .{ }^{1,3,31-33}$ Because of the increased saddling, the $\beta-\mathrm{Br}_{8}$ and $\beta$ $\left(\mathrm{CF}_{3}\right)_{8}$ complexes should undergo a stronger $\mathrm{Cu}\left(3 \mathrm{~d}_{x^{2}-y^{2}}{ }^{2}\right.$-corrole $\left(\mathrm{b}_{1}-\mathrm{HOMO}\right)$ interaction.

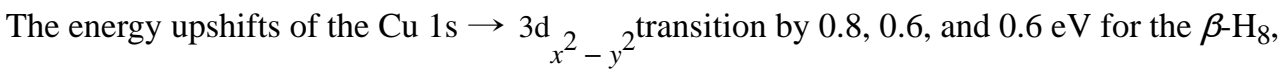
$\beta \mathrm{t}-\mathrm{Br}_{8}$, and $\beta-\left(\mathrm{CF}_{3}\right)_{8}$ substituted porphyrin/corrole pairs, respectively, a trend that is also reproduced by TDDFT with $5 \% \mathrm{HF}$ exchange $(0.7,0.4$, and $0.4 \mathrm{eV}$ energy upshifts), suggest increased $\mathrm{Cu}(\mathrm{II})$ character in $\mathrm{Cu}\left[\mathrm{Br}_{8} \mathrm{TPC}\right]$ and $\mathrm{Cu}\left[\left(\mathrm{CF}_{3}\right)_{8} \mathrm{TPC}\right]$ relative to $\mathrm{Cu}[\mathrm{TPC}]$. These energy shifts implicate a stronger $\mathrm{Cu}\left(3 \mathrm{~d}_{x^{2}}-y^{2}\right)$-corrole $\left(\mathrm{b}_{1}-\mathrm{HOMO}\right)$ interaction with increased saddling, which may imply an even stronger covalent interaction (but not necessarily spin polarization). A similar result was also found for Ag corroles in Ag L-edge XAS measurements. ${ }^{37}$

\section{EXPERIMENTAL SECTION}

\section{Sample Preparation.}

$\mathrm{H}_{2} \mathrm{TPP},{ }^{56} \mathrm{Cu}[\mathrm{TPP}],{ }^{57} \mathrm{Cu}\left[\mathrm{Br}_{8} \mathrm{TPP}\right],{ }^{58} \mathrm{Cu}\left[\left(\mathrm{CF}_{3}\right)_{8} \mathrm{TPP}\right],{ }^{59} \mathrm{H}_{3} \mathrm{TPC},{ }^{60} \mathrm{Cu}[\mathrm{TPC}],{ }^{10}$ $\mathrm{Cu}\left[\mathrm{Br}_{8} \mathrm{TPC}\right],{ }^{10}$ and $\mathrm{Cu}\left[\left(\mathrm{CF}_{3}\right) 8 \mathrm{TPC}\right]^{19,33}$ were prepared as previously described. The structures of these complexes were confirmed with UV-vis spectrophotometry, high resolution electrospray ionization mass spectrometry, and ${ }^{1} \mathrm{H}$ and ${ }^{19} \mathrm{~F}$ NMR spectroscopy.

\section{X-ray Absorption Spectroscopy.}

The $\mathrm{Cu}$ K-edge X-ray absorption spectra were collected at the Stanford Synchrotron Radiation Lightsource on the unfocused 20-pole $2 \mathrm{~T}$ wiggler beamline 7-3 under standard ring conditions of $3 \mathrm{GeV}$ and $\sim 500 \mathrm{~mA}$. A Rh-coated premonochromator mirror was used for harmonic rejection and vertical collimation. A Si(220) double-crystal monochromator was used for energy selection. Each solid sample was finely ground with boron nitride, and this homogeneous mixture was pressed into an aluminum spacer with $38 \boldsymbol{\mu}$ m Kapton tape windows. The samples were maintained at a constant temperature of $\sim 10 \mathrm{~K}$ during data collection using an Oxford Instruments CF 1208 continuous flow liquid helium cryostat. The transmission mode was used to collect data to $\boldsymbol{k}=9.5 \AA^{-1}$. Internal energy calibration was accomplished by simultaneous measurement of the absorption of a $\mathrm{Cu}$ foil placed between ionization chambers situated after the sample. The inflection point of the foil spectrum was assigned to $8980.3 \mathrm{eV}$. Spectra presented here are 2-4 scan averaged data. To prevent any photodegradation effect in the final data, only the first scans obtained from physically separated measurement spots were used for the final average.

Background subtraction and normalization of the data were performed using PySpline. ${ }^{61}$ The data were processed by fitting a second-order polynomial to the pre-edge region and subtracting this from the entire spectrum as a background. A two-region polynomial spline of orders 2 and 3 was used to model the smoothly decaying postedge region. The data were normalized by scaling the spline function to an edge jump of 1.0 at $9000 \mathrm{eV}$. The second derivatives of the $\mathrm{Cu} \mathrm{K}$ pre-edge regions were smoothed using a third-order polynomial with 
a $0.5 \mathrm{eV}$ range in the program EXAFSPAK (George, G. N. Stanford Synchrotron Radiation Laboratory: Stanford, CA, 2000).

The $\mathrm{Cu} \mathrm{K}$ pre-edge features were modeled with pseudo-Voigt line shape with a 1:1 ratio of Lorentzian/Gaussian functions using the fitting program EDG_FIT (George, G. N. Stanford Synchrotron Radiation Laboratory: Stanford, CA, 2000). To reduce the number of the variables which float during the fitting process, the half width at half-maximum (HWHM)

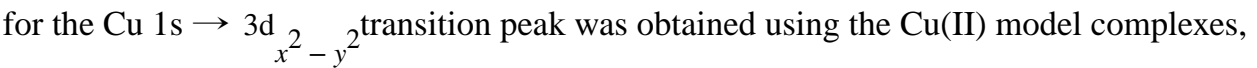
$\left[\mathrm{Cu}(\mathrm{II})\left(\mathrm{H}_{-2} \mathrm{Aib}_{3}\right)\right]_{2}(\mathrm{Aib}=$ tri- $\boldsymbol{a}$-aminoisobutyric acid $)$ and $\left[\mathrm{Cu}(\mathrm{II})_{2}(\mu-\mathrm{OH})_{2}\left(\mathrm{~L}_{\mathrm{Me} 3}-\mathrm{TACN}\right)_{2}\right]^{2+}\left(\mathrm{L}_{\mathrm{Me}}\right.$-TACN $=1,4,7$-trimethyl-1,4,7-triazacyclo-nonane $)$.

${ }^{43}$ While this obtained HWHM value $(0.91 \mathrm{eV})$ was kept constant for the lower-energy peak in the experimental spectra, other variables including the HWHM of the higher-energy peak, energy position, and peak intensity were all allowed to float throughout the fitting process. A function modeling the background was empirically chosen to give the best fit. An acceptable fit reasonably matches both the pre-edge spectrum and its second derivative. In all cases, three acceptable fits with different HWHM $( \pm 0.3$ fixed from float) backgrounds were acquired over the energy ranges 8976-8983, 8976-8984, and 8976-8985 eV resulting in a total of nine pre-edge fits per data set, which were averaged to obtain mean values.

\section{Computational Methods.}

Geometry optimizations were conducted with the ADF program ${ }^{62}$ using the BP86 63,64 functional and all-electron STO-TZP basis sets; Grimme's D3 dispersion correction was employed to account for the noncovalent interaction. ${ }^{65}$ The TDDFT calculations for the preedge region analysis were performed with the ORCA 3.0.3 program ${ }^{66}$ using the optimized structures. The latter calculations were carried out with the BP86 and B3LYP67,68 functionals and the def2-TZVP ${ }^{6}$ basis set. For the calculations with the 5\% and $10 \% \mathrm{HF}$ exchange, the amount of the HF exchange in the B3LYP functional was modified to 5\% or $10 \%$. The RIJCOSX approximation was used for the calculations with the hybrid functionals. ${ }^{70}$ The zeroth-order regular approximation (ZORA) $)^{71,72}$ for relativistic effects and the conductor-like screening model (COSMO $)^{73}$ in an infinite dielectric were included. The calculations used a dense integration grid (ORCA Grid4) and tight convergence criteria. The TDDFT calculated transitions were broadened by a Gaussian function with $1.4 \mathrm{eV}$ line width for comparison with the experimental spectra. Molecular orbitals were visualized with Lumo (http://www.kieber-emmons.com/Lumo/).

\section{Supplementary Material}

Refer to Web version on PubMed Central for supplementary material.

\section{ACKNOWLEDGMENTS}

H.L. was supported by an Abbott Laboratories Stanford Graduate Fellowship. For A.G., this work was supported by Grants 231086 and 262229 of the Research Council of Norway. For E.I.S., this work was supported by the National Institute of Diabetes and Digestive and Kidney Diseases of the National Institutes of Health under Award Number R01DK031450. The Stanford Synchrotron Radiation Light-source, SLAC National Accelerator Laboratory, is supported by the U.S. Department of Energy, Office of Science, Office of Basic Energy Sciences under Contract No. DE-AC02-76SF00515. The SSRL Structural Molecular Biology Program is supported by the DOE Office of 
Biological and Environmental Research, and by the National Institutes of Health, National Institute of General Medical Sciences (P41GM103393). The contents of this publication are solely the responsibility of the authors and do not necessarily represent the official views of the NIGMS or NIH.

\section{REFERENCES}

(1). Thomas KE; Alemayehu AB; Conradie J; Beavers CM; Ghosh A The Structural Chemistry of Metallocorroles: Combined X-ray Crystallography and Quantum Chemistry Studies Afford Unique Insights. Acc. Chem. Res. 2012, 45, 1203-1214. [PubMed: 22444488]

(2). Palmer JH Transition Metal Corrole Coordination Chemistry In Molecular Electronic Structures of Transition Metal Complexes I; Mingos DMP, Day P, Dahl JP, Eds.; Structure and Bonding; Springer Berlin Heidelberg: Berlin, Heidelberg, 2011; Vol. 142, pp 49-89.

(3). Ghosh A Electronic Structure of Corrole Derivatives: Insights from Molecular Structures, Spectroscopy, Electrochemistry, and Quantum Chemical Calculations. Chem. Rev. 2017, 117, 3798-3881. [PubMed: 28191934]

(4). Steene E; Wondimagegn T; Ghosh A Electrochemical and Electronic Absorption Spectroscopic Studies of Substituent Effects in Iron(IV) and Manganese(IV) Corroles. Do the Compounds Feature High-Valent Metal Centers or Noninnocent Corrole Ligands? Implications for Peroxidase Compound I and II Intermediates. J. Phys. Chem. B 2001, 105, 11406-11413.

(5). Ganguly S; McCormick LJ; Conradie J; Gagnon KJ; Sarangi R; Ghosh A Electronic Structure of Manganese Corroles Revisited: X-ray structures, Optical and X-ray Absorption Spectros-copies, and Electrochemistry as Probes of Ligand Noninnocence. Inorg. Chem. 2018, 57, 9656-9669. [PubMed: 29873229]

(6). Ganguly S; Thomas KE; Sarangi R; Ghosh A Ligand Noninnocence in Iron Corroles: Insights from Optical and X-ray Absorption Spectroscopies and Electrochemical Redox Potentials. Chem. - Eur. J. 2017, 23, 15098-15106. [PubMed: 28845891]

(7). Vazquez-Lima H; Norheim HK; Einrem RF; Ghosh A Cryptic Noninnocence: FeNO Corroles in a New Light. Dalton Trans. 2015, 44, 10146-10151. [PubMed: 25978788]

(8). Norheim H-K; Capar J; Einrem RF; Gagnon KJ; Beavers CM; Vazquez-Lima H; Ghosh A Ligand Noninnocence in FeNO Corroles: Insights from $\beta$-Octabromocorrole Complexes. Dalton Trans. 2016, 45, 681-689. [PubMed: 26619363]

(9). Ganguly S; Vazquez-Lima H; Ghosh A Wolves in Sheep's Clothing: $\mu$-Oxo-Diiron Corroles Revisited. Chem. - Eur. J. 2016, 22, 10336-10340. [PubMed: 27333259]

(10). Wasbotten IH; Wondimagegn T; Ghosh A Electronic Absorption, Resonance Raman, and Electrochemical Studies of Planar and Saddled Copper(III) meso-Triarylcorroles. Highly Substituent-Sensitive Soret Bands as a Distinctive Feature of High-Valent Transition Metal Corroles. J. Am. Chem. Soc. 2002, 124, 8104-8116. [PubMed: 12095356]

(11). Lemon CM; Huynh M; Maher AG; Anderson BL; Bloch ED; Powers DC; Nocera DG Electronic Structure of Copper Corroles. Angew. Chem. Int. Ed. 2016, 55, 2176-2180.

(12). Will S; Lex J; Vogel E; Schmickler H; Gisselbrecht JP; Haubtmann C; Bernard M; Gorss M Nickel and Copper Corroles: Well-Known Complexes in a New Light. Angew. Chem., Int. Ed. Engl. 1997, 36, 357-361.

(13). Brückner C; Briñas RP; Bauer JAK X-ray Structure and Variable Temperature NMR Spectra of [meso-Triarylcorrolato]-copper(III). Inorg. Chem. 2003, 42, 4495-4497. [PubMed: 12870931]

(14). Steene E; Dey A; Ghosh A $\beta$-Octafluorocorroles. J. Am. Chem. Soc. 2003, 125, 16300-16309. [PubMed: 14692771]

(15). Luobeznova I; Simkhovich L; Goldberg I; Gross Z Electronic Structures and Reactivities of Corrole-Copper Complexes. Eur. J. Inorg. Chem. 2004, 2004, 1724-1732.

(16). Bröring M; Bégier F; Tejero EC; Hell C; Holthausen MC Revisiting the Electronic Ground State of Copper Corroles. Angew. Chem., Int. Ed. 2007, 46, 445-448.

(17). Pierloot K; Zhao H; Vancoillie S Copper Corroles: The Question of Noninnocence. Inorg. Chem. 2010, 49, 10316-10329. [PubMed: 20964313] 
(18). Thomas KE; Vazquez-Lima H; Fang Y; Song Y; Gagnon KJ; Beavers CM; Kadish KM; Ghosh A Ligand Noninnocence in Coinage Metal Corroles: A Silver Knife-Edge. Chem. - Eur. J. 2015, 21, 16839-16847. [PubMed: 26345592]

(19). Thomas KE; Wasbotten IH; Ghosh A Copper $\beta$ - Octakis(trifluoromethyl)corroles: New Paradigms for Ligand Substituent Effects in Transition Metal Complexes. Inorg. Chem. 2008, 47, 10469-10478. [PubMed: 18928275]

(20). Alemayehu AB; Vazquez-Lima H; Beavers CM; Gagnon KJ; Bendix J; Ghosh A Platinum Corroles. Chem. Commun. 2014, 50, 11093-11096.

(21). Johansen I; Norheim H-K; Larsen S; Alemayehu AB; Conradie J; Ghosh A Substituent Effects on Metallocorrole Spectra: Insights from Chromium-Oxo and Molybdenum-Oxo Triarylcorroles. J. Porphyrins Phthalocyanines 2011, 15, 1335-1344.

(22). Alemayehu AB; Vazquez-Lima H; Gagnon KJ; Ghosh A Stepwise Deoxygenation of Nitrite as a Route to Two Families of Ruthenium Corroles: Group 8 Periodic Trends and Relativistic Effects. Inorg. Chem. 2017, 56, 5285-5294. [PubMed: 28422487]

(23). Alemayehu AB; Gagnon KJ; Terner J; Ghosh A Oxidative Metalation as a Route to SizeMismatched Macrocyclic Complexes: Osmium Corroles. Angew. Chem. Int. Ed. 2014, 53, 14411-14414.

(24). Einrem RF; Braband H; Fox T; Vazquez-Lima H; Alberto R; Ghosh A Synthesis and Molecular Structure of 99Tc Corroles. Chem. - Eur. J. 2016, 22, 18747-18751. [PubMed: 27802367]

(25). Einrem RF; Gagnon KJ; Alemayehu AB; Ghosh A Metal-Ligand Misfits: Facile Access to Rhenium-Oxo Corroles by Oxidative Metalation. Chem. - Eur. J. 2016, 22, 517-520. [PubMed: 26639951]

(26). Alemayehu AB; Ghosh A Gold Corroles. J. Porphyrins Phthalocyanines 2011, 15, 106-110.

(27). Rabinovich E; Goldberg I; Gross Z Gold(I) and Gold(III) Corroles. Chem. - Eur. J. 2011, 17 , 12294-12301. [PubMed: 21972002]

(28). Thomas KE; Alemayehu AB; Conradie J; Beavers C; Ghosh A Synthesis and Molecular Structure of Gold Triarylcorroles. Inorg. Chem. 2011, 50, 12844-12851. [PubMed: 22111600]

(29). Alemayehu A; Vazquez-Lima H; McCormick LJ; Ghosh A Relativistic Effects in Metallocorroles: Comparison of Molybdenum and Tungsten Biscorroles. Chem. Commun. 2017, 53, 5830-5833.

(30). Alemayehu A; Vazquez-Lima H; Gagnon KJ; Ghosh A Tungsten Biscorroles: New Chiral Sandwich Compounds. Chem. - Eur. J. 2016, 22, 6914-6920. [PubMed: 27059004]

(31). Alemayehu AB; Gonzalez E; Hansen LK; Ghosh A Copper Corroles Are Inherently Saddled. Inorg. Chem. 2009, 48, 7794-7799. [PubMed: 19618938]

(32). Alemayehu AB; Hansen LK; Ghosh A Nonplanar, Noninnocent, and Chiral: A Strongly Saddled Metallocorrole. Inorg. Chem. 2010, 49, 7608-7610. [PubMed: 20681518]

(33). Thomas KE; Conradie J; Hansen LK; Ghosh A A Metallocorrole with Orthogonal Pyrrole Rings. Eur. J. Inorg. Chem. 2011, 2011, 1865-1870.

(34). Berg S; Thomas KE; Beavers CM; Ghosh A Undecaphenylcorroles. Inorg. Chem. 2012, 51, 9911-9916. [PubMed: 22954313]

(35). Thomas KE; McCormick LJ; Carrie D; Vazquez-Lima H; Simonneaux G; Ghosh A Halterman Corroles and Their Use as a Probe of the Conformational Dynamics of the Inherently Chiral Copper Corrole Chromophore. Inorg. Chem. 2018, 57, 4270-4276. [PubMed: 29608308]

(36). Thomassen IK; McCormick LJ; Ghosh A Synthesis and Molecular Structure of a Copper Octaiodocorrole. ACS Omega 2018, 3, 5106-5110.

(37). Sarangi R; Giles LJ; Thomas KE; Ghosh A Ligand Noninnocence in Silver Corroles: A XANES Investigation. Eur. J. Inorg. Chem. 2016, 2016, 3225-3227.

(38). Ou Z; Shao J; Zhao H; Ohkubo K; Wasbotten IH; Fukuzumi S; Ghosh A; Kadish KM Spectroelectrochemical and ESR Studies of Highly Substituted Copper Corroles. J. Porphyrins Phthalocyanines 2004, 8, 1236-1247.

(39). Ganguly S; Renz D; Giles LJ; Gagnon KJ; McCormick LJ; Conradie J; Sarangi R; Ghosh A Cobalt- and Rhodium-Corrole-Triphenylphosphine Complexes Revisited: The Question of a Noninnocent Corrole. Inorg. Chem. 2017, 56, 14788-14800. [PubMed: 29210572] 
(40). Palmer JH; Lancaster KM Molecular Redox: Revisiting the Electronic Structures of the Group 9 Metallocorroles. Inorg. Chem. 2012, 51, 12473-12482. [PubMed: 23116160]

(41). Sarangi R X-ray Absorption Near-Edge Spectroscopy in Bioinorganic Chemistry: Application to M-O ${ }_{2}$ Systems. Coord. Chem. Rev. 2013, 257, 459-472. [PubMed: 23525635]

(42). Kau LS; Spira-Solomon DJ; Penner-Hahn JE; Hodgson KO; Solomon EI X-ray Absorption Edge Determination of the Oxidation State and Coordination Number of Copper: Application to the Type 3 Site in Rhus Vernicifera Laccase and Its Reaction with Oxygen. J. Am. Chem. Soc. 1987, 109, 6433-6442.

(43). DuBois JL; Mukherjee P; Stack TDP; Hedman B; Solomon EI; Hodgson KO A Systematic Kedge X-ray Absorption Spectroscopic Study of Cu(III) Sites. J. Am. Chem. Soc. 2000, 122, 5775-5787.

(44). George SD; Petrenko T; Neese F Prediction of Iron K-edge Absorption Spectra Using TimeDependent Density Functional Theory. J. Phys. Chem. A 2008, 112, 12936-12943. [PubMed: 18698746]

(45). Chandrasekaran P; Stieber SCE; Collins TJ; Que L Jr.; Neese F; DeBeer S Prediction of HighValent Iron K-edge Absorption Spectra by Time-Dependent Density Functional Theory. Dalton Trans. 2011, 40, 11070-11079. [PubMed: 21956429]

(46). Roemelt M; Beckwith MA; Duboc C; Collomb M-N; Neese F; DeBeer S Manganese K-edge Xray Absorption Spectros-copy as a Probe of the Metal-Ligand Interactions in Coordination Compounds. Inorg. Chem. 2012, 51, 680-687. [PubMed: 22145735]

(47). Lima FA; Bjornsson R; Weyhermuller T; Chandrasekaran P; Glatzel P; Neese F; DeBeer S HighResolution Molybdenum K-edge X-ray Absorption Spectroscopy Analyzed with TimeDependent Density Functional Theory. Phys. Chem. Chem. Phys. 2013, 15, 20911-20920. [PubMed: 24197060]

(48). Sinha W; Sommer MG; Deibel N; Ehret F; Bauer M; Sarkar B; Kar S Experimental and Theoretical Investigations of the Existence of $\mathrm{Cu}^{\mathrm{II}}, \mathrm{Cu}^{\mathrm{III}}$, and $\mathrm{Cu}^{\mathrm{IV}}$ in Copper Corrolato Complexes. Angew. Chem., Int. Ed. 2015, 54, 13769-13774.

(49). Tomson NC; Williams KD; Dai X; Sproules S; DeBeer S; Warren TH; Wieghardt K Reevaluating the $\mathrm{Cu} \mathrm{K}$ Pre-edge XAS Transition in Complexes with Covalent Metal-Ligand Interactions. Chem. Sci. 2015, 6, 2474-2487. [PubMed: 29308158]

(50). Walroth RC; Uebler JWH; Lancaster KM Probing $\mathrm{Cu}^{\mathrm{I}}$ Homogeneous Catalysis Using HighEnergy-Resolution Fluorescence-Detected X-ray Absorption Spectroscopy. Chem. Commun. 2015, 51, 9864-9867.

(51). Walroth RC; Lukens JT; MacMillan SN; Finkelstein KD; Lancaster KM Spectroscopic Evidence for a $3 \mathrm{~d}^{10}$ Ground State Electronic Configuration and Ligand Field Inversion in $\left[\mathrm{Cu}\left(\mathrm{CF}_{3}\right)_{4}\right]^{1-}$. J. Am. Chem. Soc. 2016, 138, 1922-1931. [PubMed: 26844693]

(52). Walroth RC; Miles KC; Lukens JT; MacMillan SN; Stahl SS; Lancaster KM Electronic Structural Analysis of Copper(II)-TEMPO/ABNO Complexes Provides Evidence for Copper(I)Oxoammonium Character. J. Am. Chem. Soc. 2017, 139, 13507-13517. [PubMed: 28921958]

(53). Sarangi R; Aboelella N; Fujisawa K; Tolman WB; Hedman B; Hodgson KO; Solomon EI X-ray Absorption Edge Spectroscopy and Computational Studies on $\mathrm{LCuO}_{2}$ Species: Superoxide-Cu II versus Peroxide-Cu ${ }^{\text {III }}$ Bonding. J. Am. Chem. Soc. 2006, 128, 8286-8296. [PubMed: 16787093]

(54). Maurya YK; Noda K; Yamasumi K; Mori S; Uchiyama T; Kamitani K; Hirai T; Ninomiya K; Nishibori M; Hori Y; Shiota Y; Yoshizawa K; Ishida M; Furuta H Ground-State Copper(III) Stabilized by N-Confused/N-Linked Corroles: Synthesis, Characterization, and Redox Reactivity. J. Am. Chem. Soc. 2018, 140, 6883-6892. [PubMed: 29749234]

(55). Larsen S; McCormick-McPherson LJ; Teat SJ; Ghosh A Azulicorrole. ACS Omega 2019, 4, 6737-6745.

(56). Adler AD; Longo FR; Finarelli JD; Goldmacher J; Assour J; Korsakoff L A Simplified Synthesis for meso- Tetraphenylporphine. J. Org. Chem. 1967, 32, 476-476.

(57). Adler AD; Longo FR; Varadi V Metaiioporphyrins; Basolo F, Ed.; Inorganic Syntheses; 2006; Vol. 16, pp 213-220.

(58). Bhyrappa P; Krishnan V Octabromotetraphenylporphyrin and Its Metal Derivatives: Electronic Structure and Electrochemical Properties. Inorg. Chem. 1991, 30, 239-245. 
(59). Liu C; Chen QY Fluoroalkylation of Porphyrins: A Facile Synthesis of Trifluoromethylated Porphyrins by a Palladium- Catalyzed Cross-Coupling Reaction. Eur. J. Org. Chem. 2005, 2005, 3680-3686.

(60). Koszarna B; Gryko DT Efficient Synthesis of meso-Substituted Corroles in a $\mathrm{H}_{2} \mathrm{O}-\mathrm{MeOH}$ Mixture. J. Org. Chem. 2006, 71, 3707-3717. [PubMed: 16674040]

(61). Tenderholt A; Hedman B; Hodgson KO PySpline: A Modern, Cross-Platform Program for the Processing of Raw Averaged XAS Edge and EXAFS Data. AIP Conf. Proc. 2006, 882, 105-107.

(62). te Velde G; Bickelhaupt FM; Baerends EJ; Fonseca Guerra C; van Gisbergen SJA; Snijders JG; Ziegler T Chemistry with ADF. J. Comput. Chem. 2001, 22, 931-967.

(63). Perdew JP Density-Functional Approximation for the Correlation Energy of the Inhomogeneous Electron Gas. Phys. Rev. B: Condens. Matter Mater. Phys. 1986, 33, 8822-8824.

(64). Becke AD Density-Functional Exchange-Energy Approximation with Correct Asymptotic Behavior. Phys. Rev. A: At., Moi., Opt. Phys. 1988, 38, 3098-3100.

(65). Grimme S; Antony J; Ehrlich S; Krieg H A Consistent and Accurate Ab Initio Parametrization of Density Functional Dispersion Correction (DFT-D) for the 94 Elements H-Pu. J. Chem. Phys. 2010, 132, 154104.

(66). Neese F The ORCA Program System. WIREs Comput. Mol. Sci. 2012, 2, 73-78.

(67). Becke AD Density-Functional Thermochemistry. III. The Role of Exact Exchange. J. Chem. Phys. 1993, 98, 5648-5652.

(68). Lee C; Yang W; Parr RG Development of the Colle-Salvetti Correlation-Energy Formula into a Functional of the Electron Density. Phys. Rev. B: Condens. Matter Mater. Phys. 1988, 37, 785 789.

(69). Pantazis DA; Chen X-Y; Landis CR; Neese F All-Electron Scalar Relativistic Basis Sets for Third-Row Transition Metal Atoms. J. Chem. Theory Comput. 2008, 4, 908-919. [PubMed: 26621232]

(70). Neese F; Wennmohs F; Hansen A; Becker U Efficient, Approximate and Parallel Hartree-Fock and Hybrid DFT Calculations. a "Chain-of-Spheres" Algorithm for the Hartree-Fock Exchange. Chem. Phys. 2009, 356, 98-109.

(71). van Lenthe E; Baerends EJ; Snijders JG Relativistic Regular Two-Component Hamiltonians. J. Chem. Phys. 1993, 99, 4597-4610.

(72). van Wüllen C Molecular Density Functional Calculations in the Regular Relativistic Approximation: Method, Application to Coinage Metal Diatomics, Hydrides, Fluorides and Chlorides, and Comparison with First-Order Relativistic Calculations. J. Chem. Phys. 1998, 109, 392-399.

(73). Klamt A; Schüürmann G COSMO: A New Approach to Dielectric Screening in Solvents with Explicit Expressions for the Screening Energy and Its Gradient. J. Chem. Soc., Perkin Trans. 2 1993, 799-805. 

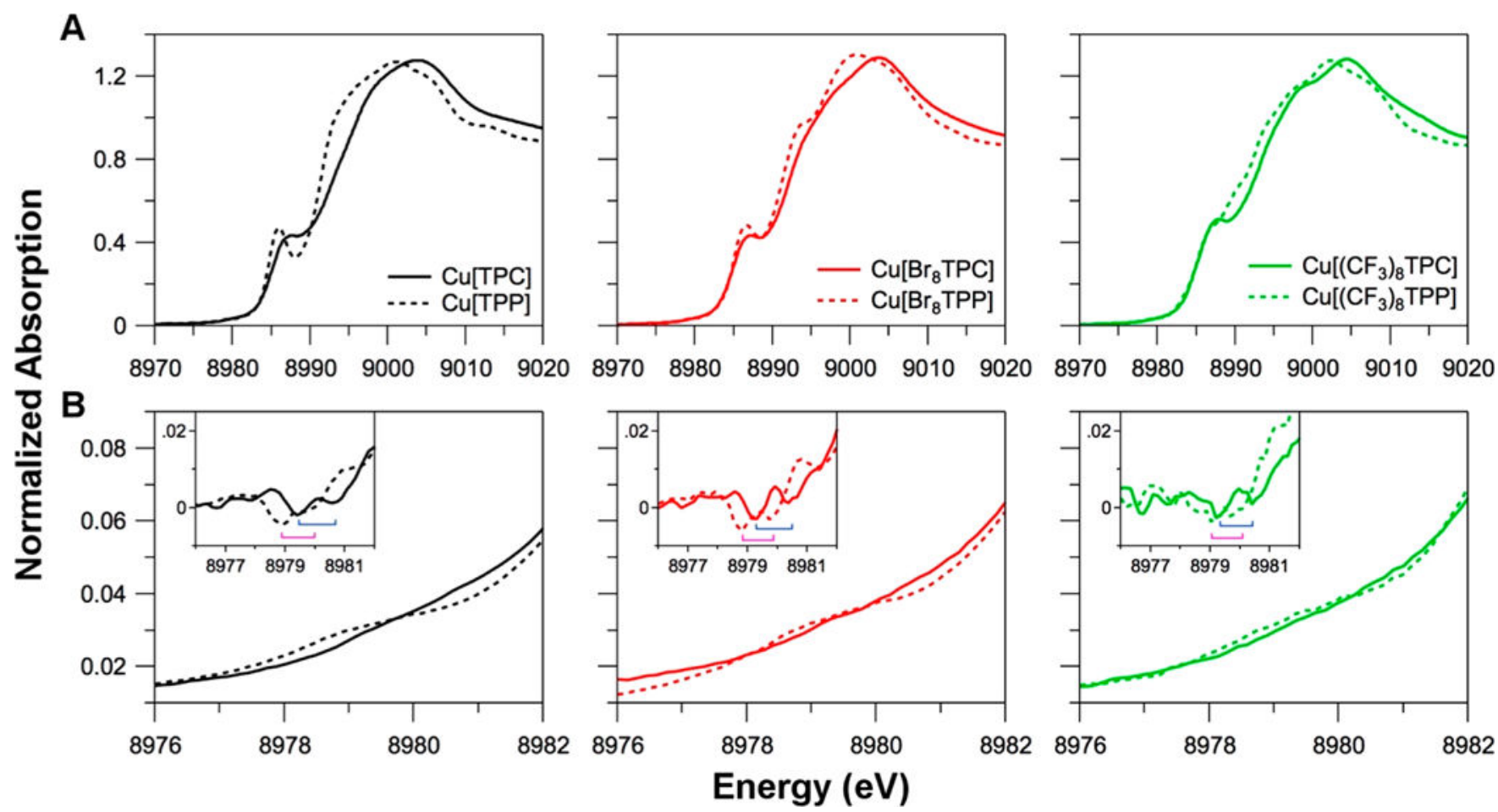

Figure 1.

$\mathrm{Cu}$ K-edge XAS spectra (A) and the expanded pre-edge regions (B) of $\mathrm{Cu}$ [TPC] (solid black), $\mathrm{Cu}[\mathrm{TPP}]$ (dotted black), $\mathrm{Cu}\left[\mathrm{Br}_{8} \mathrm{TPC}\right]$ (solid red), $\mathrm{Cu}\left[\mathrm{Br}_{8} \mathrm{TPP}\right]$ (dotted red),

$\mathrm{Cu}\left[\left(\mathrm{CF}_{3}\right)_{8} \mathrm{TPC}\right]$ (solid green), and $\mathrm{Cu}\left[\left(\mathrm{CF}_{3}\right)_{8} \mathrm{TPP}\right]$ (dotted green). Insets show the smoothed second derivative of the pre-edge region. The presence of two peaks in the pre-edge region is indicated in the insets (blue brackets for corroles and purple brackets for porphyrins). 

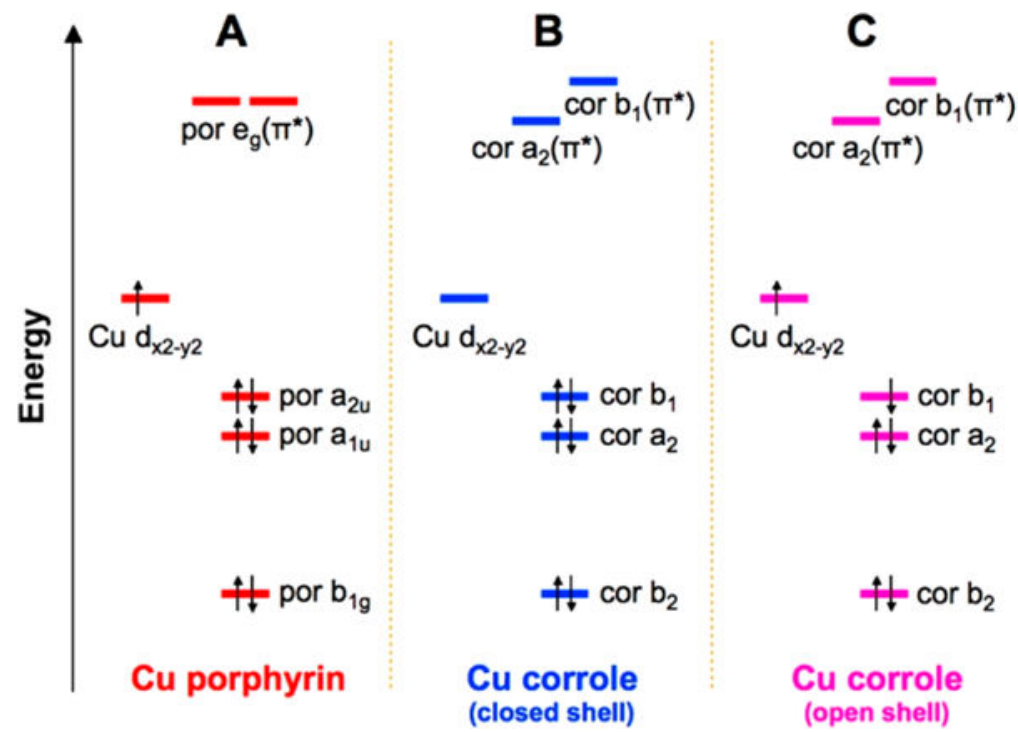

Figure 2.

Schematic energy level diagram for $\mathrm{Cu}$ porphyrin (A) and $\mathrm{Cu}$ corroie (B and $\mathrm{C}$ ) (por and cor denote porphyrin and corrole, respectively). For $\mathrm{Cu}$ corrole, two possible electronic structures are shown: (B) closed-shell description (two electrons are in corrole b with empty $\mathrm{Cu} \mathrm{d}_{x^{2}-y^{2}}$ ) and (C) open-shell description (one electron transferred from corrole $\mathrm{b}$ to $\mathrm{Cu}$ $\mathrm{d}_{x^{2}-y^{2}}$ giving antiferromagnetic exchange coupling). The energy levels for the $\mathrm{Cu} \mathrm{d} x^{2}-y^{2}$ and por/cor HOMOs are affected by different $\beta$ substituents, but the overall pattern of the energy levels remains qualitatively unaltered. For a more quantitative description, the DFT calculated energy level diagram is given in Figure S5. 

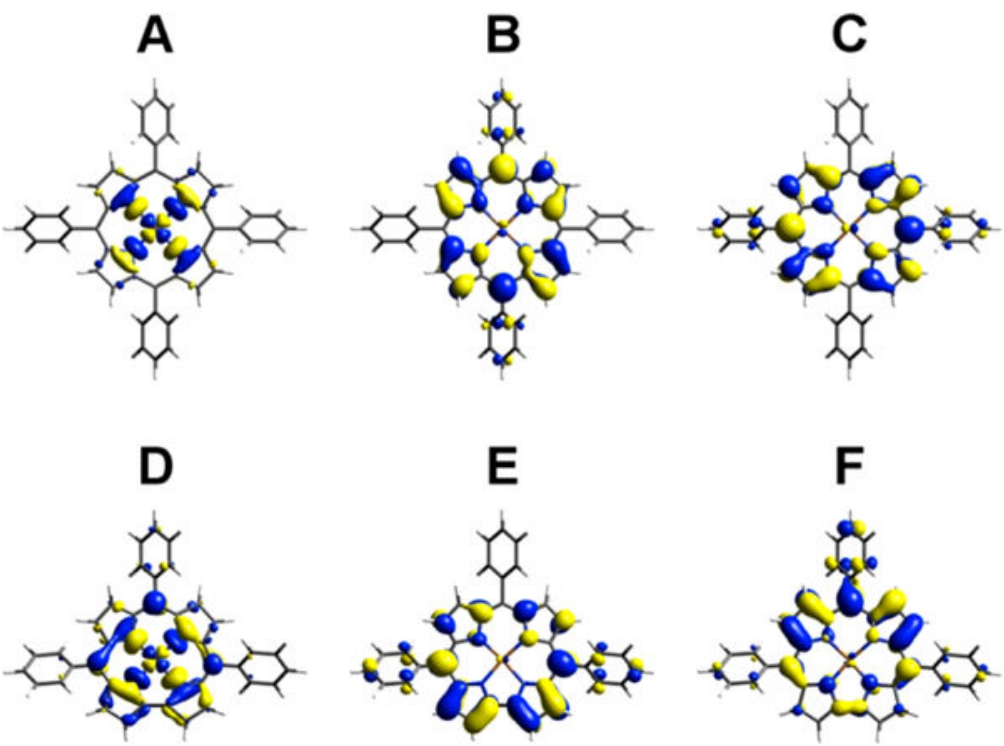

Figure 3.

Contour plots of unoccupied molecular orbitals which are associated with two peaks in the pre-edge regions for $\mathrm{Cu}[\mathrm{TPP}](\mathrm{A}, \mathrm{B}$, and $\mathrm{C}$ ) and $\mathrm{Cu}[\mathrm{TPC}](\mathrm{D}, \mathrm{E}$, and $\mathrm{F})$. $\mathrm{A}$ and $\mathrm{D}$ are molecular orbitals having significant $\mathrm{Cu} 3 \mathrm{~d}_{x^{2}-y^{2}}$ character for $\mathrm{Cu}[\mathrm{TPP}]$ and $\mathrm{Cu}[\mathrm{TPC}]$,

respectively. B, C, E, and F are porphyrin/corrole $\pi^{*}$ orbitals (B and C for $\mathrm{e}_{\mathrm{g}}$ of $\mathrm{Cu}[\mathrm{TPP}]$; E and $\mathrm{F}$ for $\mathrm{a}_{2}$ and $\mathrm{b}_{v}$ respectively, of $\left.\mathrm{Cu}[\mathrm{TPC}]\right)$. 


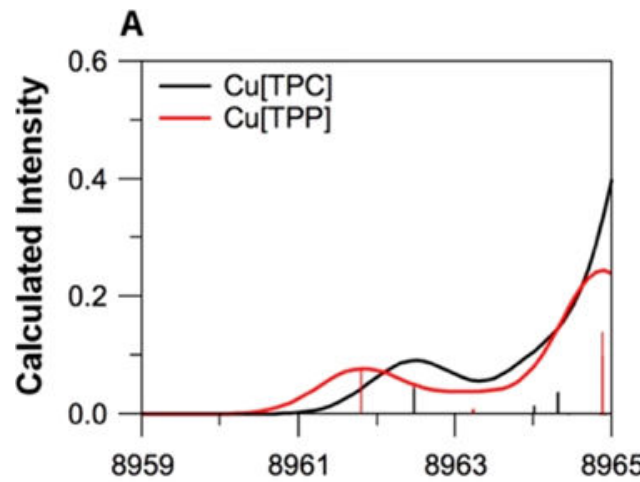

B
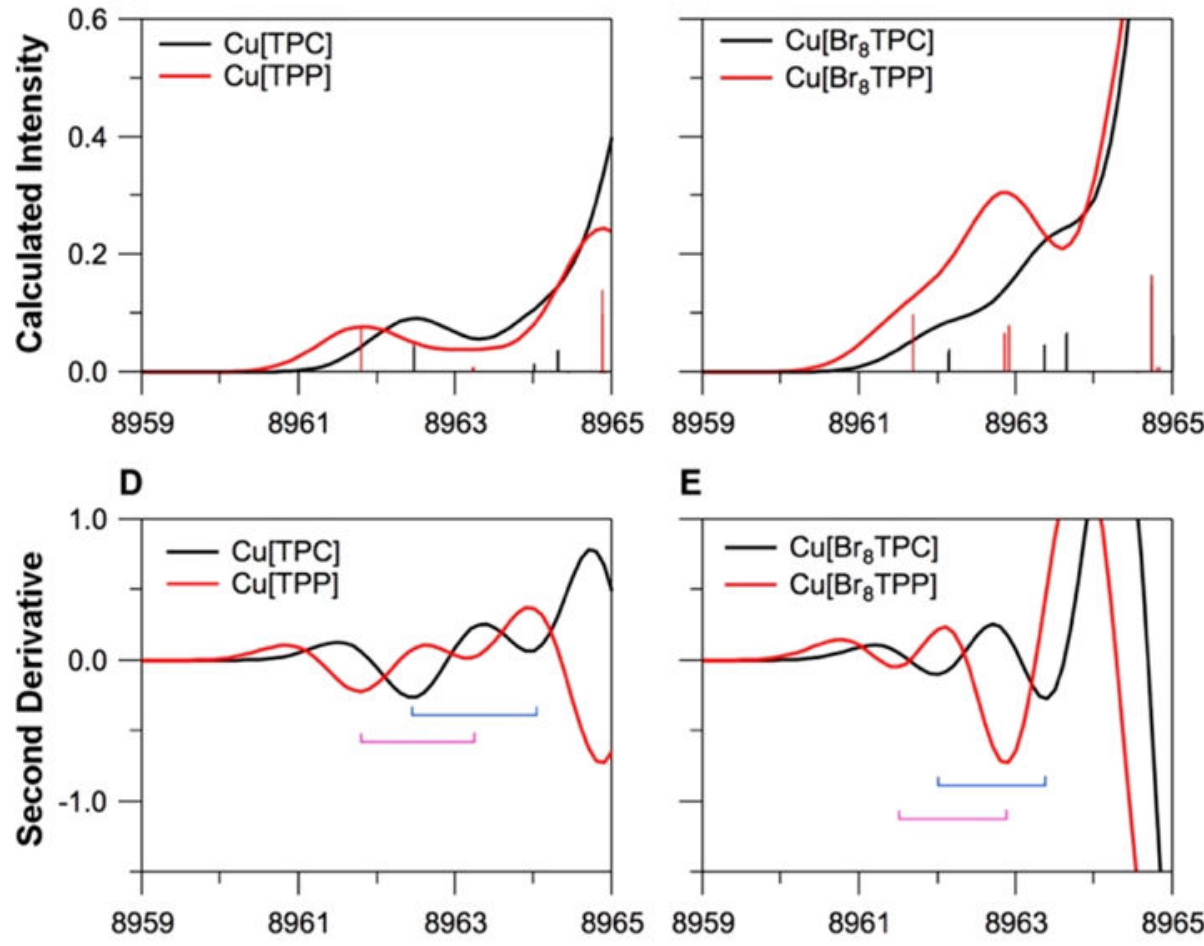

E

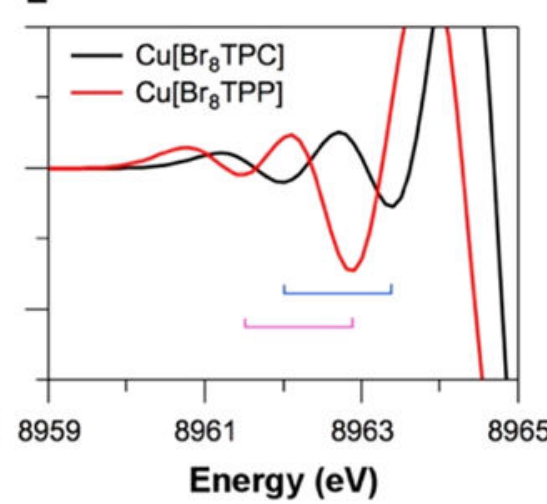

C

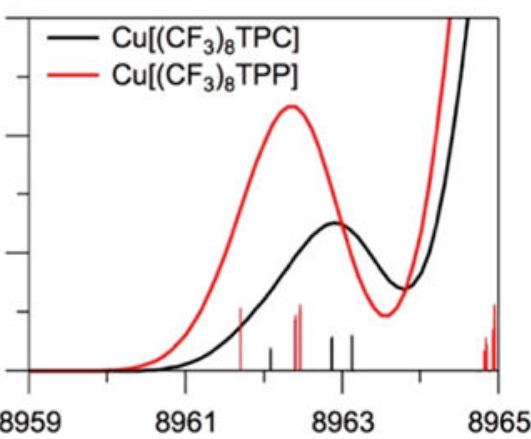

$\mathbf{F}$

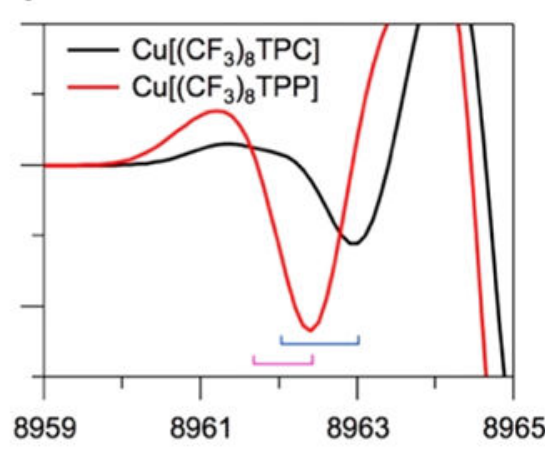

Figure 4.

Pre-edge regions (A, B, and $\mathrm{C}$ ) and their second derivatives $(\mathrm{D}, \mathrm{E}$, and $\mathrm{F}$ ) calculated using TDDFT with $5 \%$ HF exchange. The presence of two peaks in the pre-edge region is indicated in the second derivative plots by blue brackets for corroles and purple brackets for porphyrins. 


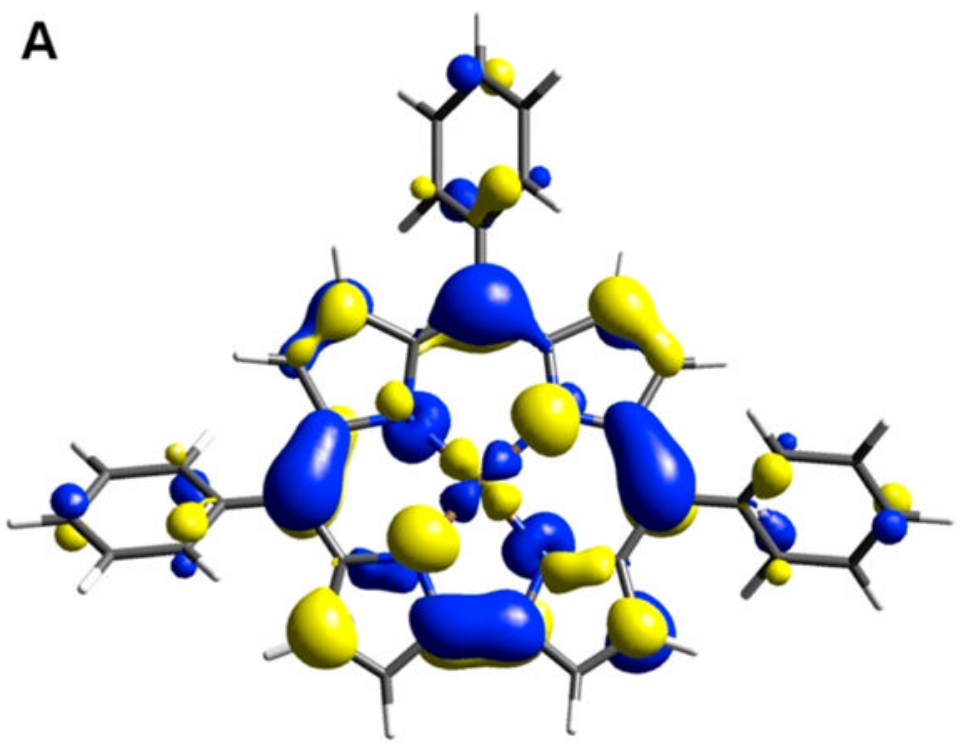

B

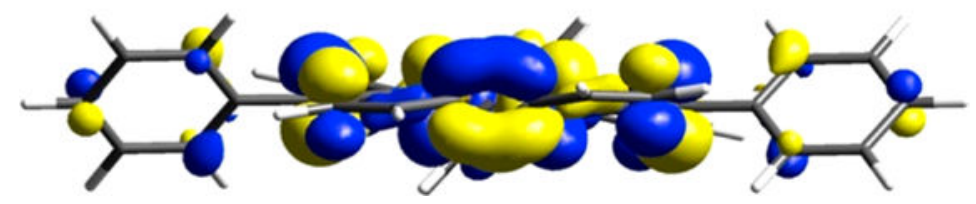

Figure 5.

Contour plot of HOMO of $\mathrm{Cu}[\mathrm{TPC}]$ from TDDFT with 5\% HF exchange (A: top view and B: side view). This shows a $\sigma-\pi$ interaction between the $\mathrm{Cu} 3 \mathrm{~d}_{x^{2}-y^{2}}$ orbital and the corrole $\mathrm{b}_{1} \mathrm{HOMO}$ from saddling. 


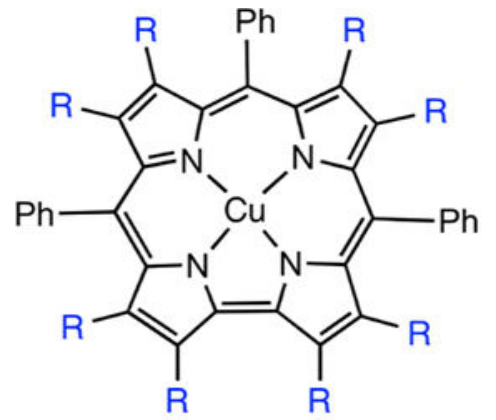

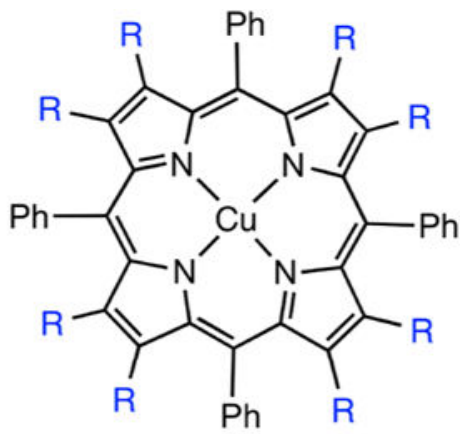

$$
\begin{array}{ll}
\mathrm{R}=\mathrm{H}: & \mathrm{Cu}[\mathrm{TPC}] \\
\mathrm{R}=\mathrm{Br}: & \mathrm{Cu}\left[\mathrm{Br}_{8} \mathrm{TPC}\right] \\
\mathrm{R}=\mathrm{CF}_{3}: \mathrm{Cu}\left[\left(\mathrm{CF}_{3}\right)_{8} \mathrm{TPC}\right]
\end{array}
$$

$$
\begin{array}{ll}
\mathrm{R}=\mathrm{H}: & \mathrm{Cu}[\mathrm{TPP}] \\
\mathrm{R}=\mathrm{Br}: & \mathrm{Cu}\left[\mathrm{Br}_{8} \mathrm{TPP}\right] \\
\mathrm{R}=\mathrm{CF}_{3}: \mathrm{Cu}\left[\left(\mathrm{CF}_{3}\right)_{8} \mathrm{TPP}\right]
\end{array}
$$

Chart 1.

Structures of $\mathrm{Cu}$ Corroles and Cu Porphyrins Used in This Study 
Table 1.

\begin{tabular}{|c|c|c|c|}
\hline & XAS Pre-edge & Energies ${ }^{a}$ & \\
\hline & & peak $1(\mathrm{eV})$ & peak $2(\mathrm{eV})$ \\
\hline & $\mathrm{Cu}[\mathrm{TPC}]$ & 8979.7 & 8980.9 \\
\hline & $\mathrm{Cu}\left[\mathrm{Br}_{8} \mathrm{TPC}\right]$ & 8979.3 & 8980.6 \\
\hline & $\mathrm{Cu}\left[\left(\mathrm{CF}_{3}\right)_{8} \mathrm{TPC}\right]$ & 8979.3 & 8980.5 \\
\hline & $\mathrm{Cu}[\mathrm{TPP}]$ & 8978.9 & 8979.9 \\
\hline & $\mathrm{Cu}\left[\mathrm{Br}_{8} \mathrm{TPP}\right]$ & 8978.7 & 8979.5 \\
\hline & $\mathrm{Cu}\left[\left(\mathrm{CF}_{3}\right)_{8} \mathrm{TPP}\right]$ & 8978.7 & 8979.7 \\
\hline
\end{tabular}

${ }^{a}$ Pre-edge peaks were modeled using EDG_FIT as described in the Experimental Section. Peak energies are listed at maximum. 


\section{롤 \\ 골}

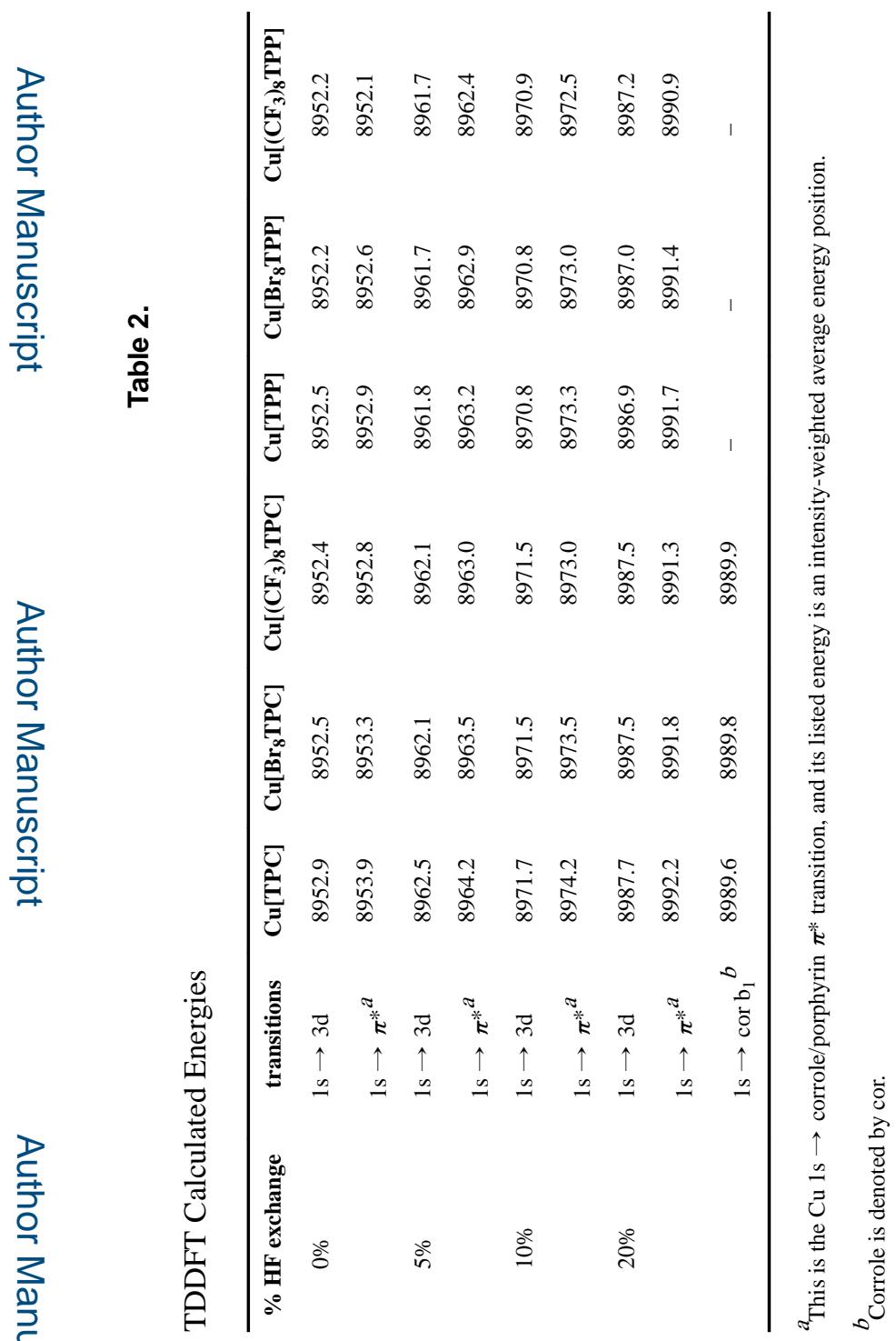

Inorg Chem. Author manuscript; available in PMC 2019 July 22. 